Article

\title{
[Rh(L-alaninate)(1,5-Cyclooctadiene)] Catalyzed Helix-Sense-Selective Polymerizations of Achiral Phenylacetylenes
}

\author{
Qingyu Wang ${ }^{1}$, Hongge Jia ${ }^{1, *}$, Yongqiang Shi ${ }^{2, *}$, Liqun Ma ${ }^{1}$, Guoxing Yang ${ }^{3}$, Yazhen Wang ${ }^{1}$, \\ Shuangping $\mathrm{Xu}{ }^{1}$, Jianjun Wang ${ }^{1}$, Yu Zang ${ }^{1}$ and Toshiki Aoki ${ }^{1,4}$ \\ 1 College of Materials Science and Engineering, College of Chemistry and Chemical Engineering, \\ Heilongjiang Province Key Laboratory of Polymeric Composition Material, Qiqihar University, \\ Qiqihar 161006, China; wqy199323@163.com (Q.W.); maliqun6166@163.com (L.M.); \\ wyz6166@163.com (Y.W.); xshp_1979_1999@163.com (S.X.); wangjianjun860505@163.com (J.W.); \\ zangyu25@163.com (Y.Z.); toshaoki@eng.niigata-u.ac.jp (T.A.) \\ 2 Department of Materials Science and Engineering and The Shenzhen Key Laboratory for Printed Organic \\ Electronics, South University of Science and Technology of China, Shenzhen 518055, China \\ 3 Daqing Petrochemical Research Center, Petrochemical Research Institute, \\ China National Petroleum Corporation, Daqing 163714, China; ygx459@petrochina.com.cn \\ 4 Graduate School of Science and Technology, Niigata University, Niigata 950-2181, Japan \\ * Correspondence: 15846287946@163.com (H.J.); xiaohangqiang@163.com (Y.S.); \\ Tel.: +86-452-2738752 (H.J.); +86-183-45293620 (Y.S.)
}

Received: 19 October 2018; Accepted: 31 October 2018; Published: 3 November 2018

check for updates

\begin{abstract}
The $[\mathrm{Rh}(\mathrm{L}$-alaninate)(cod)] (cod = 1,5-Cyclooctadiene) complex was synthesized and characterized. Asymmetric polymerizations of achiral phenylacetylene with two hydroxyl groups and a dodecyl group (DoDHPA) were performed by using the rhodium complex as the catalyst to provide polymers with a higher molecular weight $\left(>10^{5}\right)$ than the polymers obtained using the $[\mathrm{Rh}(\mathrm{cod}) \mathrm{Cl}]_{2}$ initiator systems. The resulting polymers showed circular dichroism (CD) signals at approximately 310 and $470 \mathrm{~nm}$, indicating that they have a preferential one-handed helical structure. The helix sense in the polymer main chain was controlled by the sign of the catalyst chirality. These findings suggest that the rhodium complex with a chiral amine is the true active species for the helix-sense-selective polymerization of DoDHPA. The [Rh(L-alaninate)(cod)] complex also exhibits high catalytic activity in the polymerization of phenylacetylene (PA) to give a high yield and molecular weight. All these results demonstrate that this Rh complex is an excellent catalyst for the polymerization of phenylacetylene monomers.
\end{abstract}

Keywords: helix-sense-selective polymerization; phenylacetylene; chiral rhodium catalyst; L-alaninate

\section{Introduction}

Asymmetric catalysis is one of the best methods for the synthesis of optically active organic compounds [1,2]. The design and development of novel catalytic systems for asymmetric synthesis and polymerizations have been active research areas in recent years [3-10]. In particular, in the field of phenylacetylene (PA) asymmetric polymerizations, Rh catalysts have been found to play a vital role and cannot be replaced by other metal catalysts [11].

T. Aoki et al. [12] polymerized p-dodecyloxy-m,m-dihydroxyphenylacetylene (DoDHPA) by $\left[\mathrm{Rh}(\mathrm{nbd}) \mathrm{Cl}_{2} /(\mathrm{S})-\mathrm{PEA}\right.$ (here, nbd is 2,5-norbornadiene and PEA is 1-phenylethylamine) to produce the corresponding polymer that exhibited large cotton effects in the circular dichroism (CD) spectra. The polymerization was named helix-sense-selective polymerization (HSSP). In this HSSP, the chirality 
sign of the formed main chain was controlled by the chirality (R) or (S) of the PEA cocatalyst. The authors speculated that (R) or (S)-PEA coordinates to the rhodium catalyst, and the formed complex may be a chiral catalytic center in HSSP [12,13]. Self-helix-sense-selective polymerization (SHSSP) was also carried out for phenylacetylenes with an L-amino ether residue and two hydroxy groups (ORDHPAs: OADHPA, OVDHPA, and OPDHPA) [13] (Chart S1, Supplementary Materials) by using the achiral $\left[\mathrm{Rh}(\mathrm{nbd}) \mathrm{Cl}_{2}\right.$ catalytic system. The chiral amino ether residues in the monomer and the resulting polymers were thought to act as the ligand and cocatalyst of HSSP instead of (R)-and (S)-PEA. However, the mechanism of SHSSP was not proven directly. Therefore, isolation of the real active species of HSSP or SHSSP was desired but was difficult due to the low stability of the Rh-amine complex [14,15].

T. Masuda and coworkers have designed and developed $\mathrm{Rh}$ catalyst systems for the polymerizations of substituted acetylenes in the past several years [7,9]. Two types of catalysts, namely, $[\mathrm{Rh}(\mathrm{nbd}) \mathrm{Cl}]_{2}$ and $(\mathrm{nbd}) \mathrm{Rh}^{+}\left[\eta^{6}-\left(\mathrm{C}_{6} \mathrm{H}_{5}\right) \mathrm{B}^{-}\left(\mathrm{C}_{6} \mathrm{H}_{5}\right)_{3}\right]$, were synthesized; here, the diene ligands were commonly 2,5-norbornadiene (nbd), 1,5-cyclooctadiene (cod), endo-dicyclopentadiene $(\mathrm{dcp})$, tetrafluorobenzobarrelene $(\mathrm{tfb})$, and tetrachlorobenzobarrelene $(\mathrm{tcb})$. The complexes (tfb) $\mathrm{Rh}^{+}\left[\eta^{6}-\left(\mathrm{C}_{6} \mathrm{H}_{5}\right) \mathrm{B}^{-}\left(\mathrm{C}_{6} \mathrm{H}_{5}\right)_{3}\right]$ and $(\mathrm{tcb}) \mathrm{Rh}^{+}\left[\eta^{6}-\left(\mathrm{C}_{6} \mathrm{H}_{5}\right) \mathrm{B}^{-}\left(\mathrm{C}_{6} \mathrm{H}_{5}\right)_{3}\right]$ can induce helix-sense-selective polymerization of DoDHPA, but these catalysts were not crystallized from the reaction mixture [7]. M. A. Casado polymerized PA by using a rhodium complex with mixed anionic $\mathrm{N}-\mathrm{O}$ bidentate ligands. However, the catalyst was not isolated from the ternary systems [10]. The rhodium complex of $\mathrm{tfb}$ $\left(\left[\mathrm{Rh}(\mathrm{tfb}) \mathrm{Cl}_{2}\right)\right.$ is more catalytically active than the corresponding nbd complex in the polymerization of terminal alkynes $\left(\left[\mathrm{Rh}(\mathrm{nbd}) \mathrm{Cl}_{2}\right)\right.$. However, chiral ligands have been developed for the transition metals that have displayed high activity and enantioselectivity in catalytic asymmetric reactions [11,14].

In this paper, we report for the first time the crystal chiral [Rh(L-alaninate)(cod)] ( $\operatorname{cod}=1,5$-Cyclooctadiene) catalyst (see Scheme 1$)$ that is very easily obtained and is suitable for the asymmetric polymerization of DoDHPA. The catalytic efficiency for DoDHPA and PA was found to be very high.

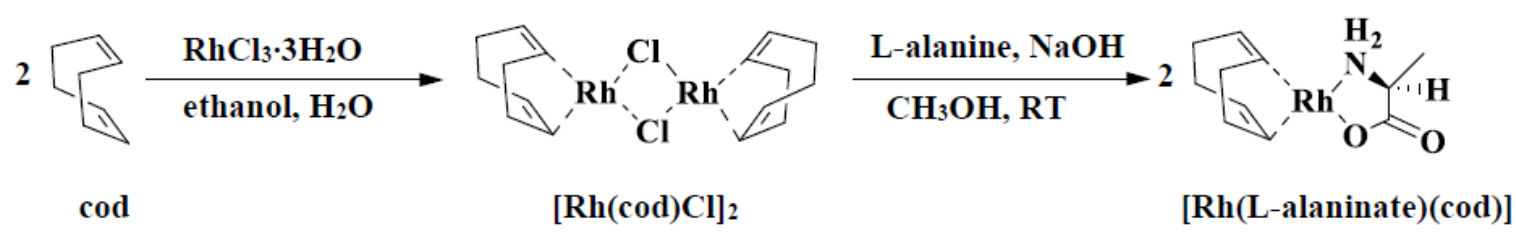

Scheme 1. Synthetic route to catalyst [Rh(L-alaninate)(cod)].

\section{Experimental Section}

All solvents were dried using standard methods and were distilled over $\mathrm{CaH}_{2}$ under reduced pressure prior to use. Commercially available compounds were used without further purification. $\mathrm{RhCl}_{3} \cdot 3 \mathrm{H}_{2} \mathrm{O}$ and all other chemicals products including the L-amino acids and $\mathbf{P A}$ were purchased from Shanghai Darui Finechem Co., Ltd. (Darui, Shanghai, China).

According to Scheme 1, the [Rh(L-alaninate)(cod)] complex was synthesized and isolated; the following reaction procedures were conducted under dry nitrogen.

$\left[\mathrm{Rh}(\operatorname{cod}) \mathrm{Cl}_{2}\right.$ : The compound was synthesized and purified according to the procedure reported in the literature (see Figure 1A; Figures S1 and S2, Supplementary Materials) [16].

[Rh(L-alaninate)(cod)]: A solution of L-alanine $(13.20 \mathrm{mg}, 0.130 \mathrm{mmol})$ and $\mathrm{NaOH}(5.50 \mathrm{mg}$, $0.130 \mathrm{mmol})$ in $\mathrm{H}_{2} \mathrm{O}(0.60 \mathrm{~mL})$ was added to a yellow suspension of $[\mathrm{Rh}(\mathrm{cod}) \mathrm{Cl}]_{2}(30.00 \mathrm{mg}, 0.06 \mathrm{mmol})$ in methanol $(2.00 \mathrm{~mL})$. The obtained clear yellow solution was stirred for $1 \mathrm{~h}$ at room temperature. The mixture was cooled at $5{ }^{\circ} \mathrm{C}$ until precipitation out from methanol, and then the precipitate was isolated by centrifugation. The product was obtained as a yellow powder $(30.00 \mathrm{mg}, 0.100 \mathrm{mmol}$, 77.9\%). ${ }^{1} \mathrm{H}$ NMR (600 MHz, DMSO- $d_{6}$, TMS, $\delta$ ): $3.89(\mathrm{br}, 4 \mathrm{H}, \mathrm{CH}=\mathrm{CH}), 3.66\left(\mathrm{br}, 2 \mathrm{H}, \mathrm{CH}_{3} \mathrm{CHNH}_{2}\right)$, $3.07\left(\mathrm{~m}, 1 \mathrm{H}, \mathrm{CH}_{3} \mathrm{CHNH}_{2}\right), 2.29\left(\mathrm{~m}, 4 \mathrm{H}, \mathrm{CH}_{2} \mathrm{CH}_{2}\right), 1.67-1.71\left(\mathrm{~d}, 4 \mathrm{H}, \mathrm{CH}_{2} \mathrm{CH}_{2}\right), 1.16\left(\mathrm{~d}, 3 \mathrm{H}, \mathrm{CH}_{3}\right)$ 
(see Figure 1B). ${ }^{13} \mathrm{C}$ NMR (150 MHz, DMSO- $\left.d_{6}, \mathrm{TMS}, \delta\right): 183.70(\mathrm{COO}), 129.04(\mathrm{CH}=\mathrm{CH}), 52.93$ $\left(\mathrm{CH}_{3} \mathrm{CH}\right), 30.60\left(\mathrm{CH}_{2} \mathrm{CH}_{2}\right), 20.92\left(\mathrm{CH}_{3} \mathrm{CH}\right)$ (Figure S3, Supplementary Materials). IR (KBr): 3444.85, 3257.97, 2935.18, 2877.26, 2830.19, 1633.71, 1572.32, 1382.10, 1339.62, 1284.56, 1186.59, 1112.61, 963.04, $856.67 \mathrm{~cm}^{-1}$ (Figure 44 , Supplementary Materials). Elemental analyses for $\mathrm{C}_{11} \mathrm{H}_{18} \mathrm{NO}_{2} \mathrm{Rh}$ : calc., \%: C 44.16, H 6.02, N 4.68; found, \%: C 44.73, H 5.13, N 4.82.

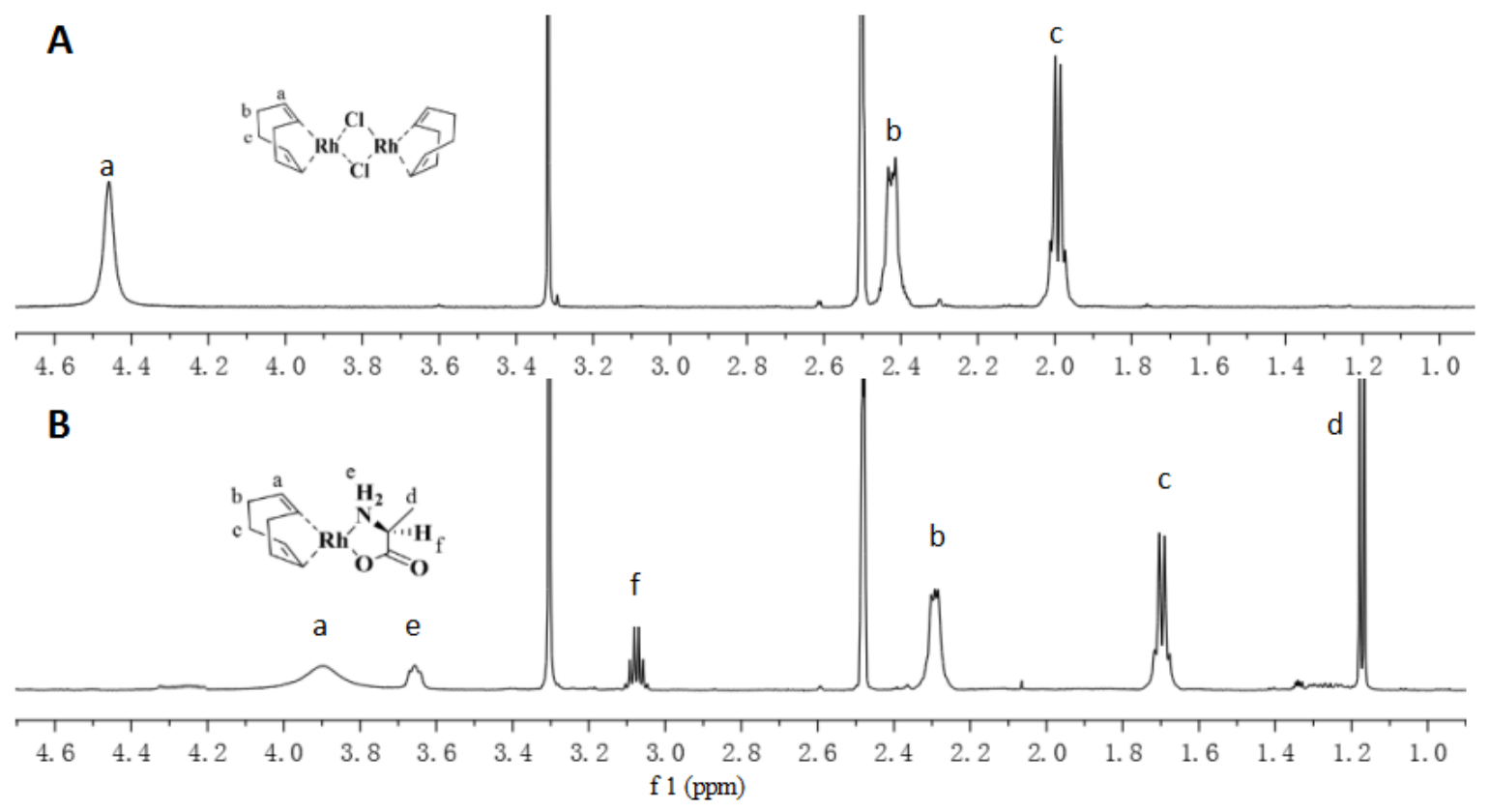

Figure 1. (A) ${ }^{1} \mathrm{H}$ NMR spectra of $[\mathrm{Rh}(\mathrm{cod}) \mathrm{Cl}]_{2}$ and (B) $\left[\mathrm{Rh}(\mathrm{L}\right.$-alaninate)(cod) $]$ in DMSO- $d_{6}$ at $25^{\circ} \mathrm{C}$.

[Rh(L-alaninate)(nbd)]: A solution of L-alanine $(12.20 \mathrm{mg}, 0.130 \mathrm{mmol})$ and $\mathrm{NaOH}(5.20 \mathrm{mg}$, $0.130 \mathrm{mmol})$ in $\mathrm{H}_{2} \mathrm{O}(0.60 \mathrm{~mL})$ was added to a yellow suspension of $[\mathrm{Rh}(\mathrm{nbd}) \mathrm{Cl}]_{2}(35.40 \mathrm{mg}, 0.070 \mathrm{mmol})$ in methanol $(2.00 \mathrm{~mL})$. The obtained clear yellow solution was stirred for $1 \mathrm{~h}$ at room temperature. The mixture was cooled at $5{ }^{\circ} \mathrm{C}$ until precipitation out from methanol, and then the precipitate was isolated by centrifugation. The product was obtained as a light yellow powder $(18.85 \mathrm{mg}, 0.070 \mathrm{mmol}$, $39.6 \%$ ) (Scheme S1, Supplementary Materials). ${ }^{1} \mathrm{H}$ NMR (600 MHz, DMSO- $\left.d_{6}, \mathrm{TMS}, \delta\right): 4.03(\mathrm{~m}, 4 \mathrm{H}$, $\mathrm{CHCH}=\mathrm{CHCH}), 3.61\left(\mathrm{~s}, 2 \mathrm{H}, \mathrm{CH}_{3} \mathrm{CHNH}_{2}\right), 2.40\left(\mathrm{~m}, 1 \mathrm{H}, \mathrm{CH}_{3} \mathrm{CHNH}_{2}\right), 1.98\left(\mathrm{~s}, 2 \mathrm{H}, \mathrm{CHCH}_{2} \mathrm{CH}\right), 1.17(\mathrm{t}$, $2 \mathrm{H}, \mathrm{CHCH}_{2} \mathrm{CH}$ ), 0.92 (t, 3H, $\mathrm{CH}_{3} \mathrm{CHNH}_{2}$ ) (Figure S5, Supplementary Materials). IR (KBr): 3427.41, 2923.77, 2857.82, 1618.95, 1452.57, 1382.12, 1286.94, 1196.25, 1080.09, 999.89, $798.29 \mathrm{~cm}^{-1}$ (Figure S6, Supplementary Materials). Elemental analyses for $\mathrm{C}_{10} \mathrm{H}_{14} \mathrm{NO}_{2} \mathrm{Rh}$ : calc., \%: C 42.42, $\mathrm{H} 4.95, \mathrm{~N} 4.95$; found, \%: C 45.87, H 6.03, N 4.52.

The achiral monomer DoDHPA was synthesized as described previously [12]. Yield $46.0 \%$. ${ }^{1} \mathrm{H}-\mathrm{NMR}\left(600 \mathrm{MHz}, \mathrm{CDCl}_{3}\right.$, TMS, 8$): 7.49$ (s, 2H, PhH), $4.70\left(\mathrm{~s}, 4 \mathrm{H}, \mathrm{CH}_{2} \mathrm{OH}\right), 3.88\left(\mathrm{t}, 2 \mathrm{H}, \mathrm{OCH}_{2} \mathrm{CH}_{2}\right)$, 3.05 (s, $1 \mathrm{H}, \mathrm{C} \equiv \mathrm{CH}), 1.93\left(\mathrm{br}, 2 \mathrm{H}, \mathrm{CH}_{2} \mathrm{OH}\right), 1.78\left(\mathrm{~m}, 2 \mathrm{H}, \mathrm{OCH}_{2} \mathrm{CH}_{2} \mathrm{CH}_{2}\right), 1.26-1.48$ (br, $18 \mathrm{H}$, $\left.\mathrm{OC}_{2} \mathrm{H}_{4}\left(\mathrm{CH}_{2}\right)_{9} \mathrm{CH}_{3}\right), 0.88$ (t, 3H, $\mathrm{CH}_{3}$ ) (Figure $\mathrm{S}$, Supplementary Materials). IR(KBr): 3356.96, 3296.25, 2918.52, 2853.32, 1463.06, 1357.39, 1211.24, 1140.79, 1055.35, 1014.88, 898.72, 803.53, 717.34, 657.39, $611.67 \mathrm{~cm}^{-1}$ (Figure S8, Supplementary Materials).

Polymerization: DoDHPA and PA were polymerized by using [Rh(L-alaninate)(cod)] and $\left[\mathrm{Rh}(\operatorname{cod}) \mathrm{Cl}_{2}\right.$. A typical polymerization procedure was as follows: a solution $(0.20 \mathrm{~mL})$ of [Rh(L-alaninate)(cod)] $(0.17 \mathrm{mg}, 0.577 \mu \mathrm{mol})$ in dry toluene was added to a dry toluene solution $(0.40 \mathrm{~mL})$ of DoDHPA $(20.00 \mathrm{mg}, 57.700 \mu \mathrm{mol})$. Polymerization was performed at $35^{\circ} \mathrm{C}$ for $24 \mathrm{~h}$. The formed polymer was isolated by precipitation in a large amount of methanol, centrifuged and dried under vacuum to a constant weight. ${ }^{1} \mathrm{H}$ NMR $\left(600 \mathrm{MHz}, 1,2\right.$-dichlorobenzene- $\left.d_{4}, \mathrm{TMS}, \delta\right)$ : $7.33(\mathrm{~s}, 2 \mathrm{H}, \mathrm{PhH}), 6.18-5.63(\mathrm{~m}, 1 \mathrm{H}, \mathrm{PhC}=\mathrm{CH}), 4.95\left(\mathrm{~s}, 4 \mathrm{H}, \mathrm{CH}_{2} \mathrm{OH}\right), 4.06\left(\mathrm{t}, 2 \mathrm{H}, \mathrm{OCH}_{2} \mathrm{CH}_{2}\right), 1.77$ $\left(\mathrm{t}, 2 \mathrm{H}, \mathrm{CH}_{2} \mathrm{OH}\right), 1.59\left(\mathrm{~s}, 2 \mathrm{H}, \mathrm{OCH}_{2} \mathrm{CH}_{2} \mathrm{CH}_{2}\right), 1.11-1.23\left(\mathrm{~m}, 18 \mathrm{H}, \mathrm{OC}_{2} \mathrm{H}_{4}\left(\mathrm{CH}_{2}\right)_{9} \mathrm{CH}_{3}\right), 0.53(\mathrm{t}, 3 \mathrm{H}$, 
$\mathrm{CH}_{3}$ ) (Figure S9, Supplementary Materials). IR (KBr): 3351.22, 2924.05, 2853.28, 1603.86, 1464.87, $1382.03,1352.11,1299.25,1211.92,1150.04,1069.08,1042.90,986.98,913.62,835.98 \mathrm{~cm}^{-1}$ (Figure S10, Supplementary Materials).

\section{Instruments}

The number and weight-averaged molecular weights ( $M_{\mathrm{n}}$ and $M_{\mathrm{w}}$, respectively) and dispersity $\left(M_{\mathrm{W}} / M_{\mathrm{n}}\right)$ of the polymers were measured by gel permeation chromatography (GPC) (Polymer Laboratories, United Kingdom) at $40{ }^{\circ} \mathrm{C}$. A nuclear magnetic resonance (Mode, Bruker, Germany) instrument $\left({ }^{1} \mathrm{H}\right.$ NMR and $\left.{ }^{13} \mathrm{C} N M R\right)$ was used to determine the molecular structure of the monomer and the catalysts. Infrared spectra were recorded using an IR-spectrum One B (PE, Austin, TX, USA) instrument. CD spectra were recorded using a MOS-450 (Bio-Logic, Seyssinet-Pariset, France) instrument. SEM images were recorded using an S-4300 (Hitachi, Tokyo, Japan) apparatus. XRD spectra were recorded using a D8-FOCUS (Bruker, Karlsruhe, Germany) instrument. Mass spectra were recorded using an UltiMate 3000 UPLC/Q-Exactive Orbitrap MS (Thermo, Hampton, NH, USA) instrument.

\section{Results and Discussion}

In this work, the rhodium catalyst [ $\mathrm{Rh}(\mathrm{L}$-alaninate)(cod)] was purified using the recrystallization method [17-20]. The isolated [Rh(L-alaninate)(cod)] complex was a yellow powder, that was crystallized from dichloromethane. The catalyst has a polygonal shape, and the crystal surface is very smooth (Figure S11, Supplementary Materials). The XRD spectrum showed good crystallizing effect (Figure S12, Supplementary Materials). The mass spectrum showed that the peak at 299 corresponds to the formation of [Rh(L-alaninate)(cod)] (Figure S13, Supplementary Materials). The [Rh(L-alaninate)(nbd)] complex achieved similar results with [Rh(L-alaninate)(cod)] (Figures S14 and S15, Supplementary Materials). We concluded that the crystals of the catalysts were obtained by the recrystallization.

The ${ }^{1} \mathrm{H}-\mathrm{NMR}$ spectrum (Figure 1$)$ of the $\left[\mathrm{Rh}\left(\mathrm{L}\right.\right.$-alaninate)(cod)] dissolved in DMSO- $d_{6}$ was obtained. The peaks of $\left(-\mathrm{CH}_{3}\right)$, amino group $(-\mathrm{NH})$ and methyne $(-\mathrm{CH})$ in L-alaninate appeared separately at $1.16-1.17 \mathrm{ppm}, 3.66 \mathrm{ppm}$ and $3.07-3.08 \mathrm{ppm}$. The coordination of L-alanine to rhodium is supported. When L-alanine was coordinated to rhodium, the chemical shift of the olefinic and methylene protons in cod changed from 4.45, 2.43, and $1.99 \mathrm{ppm}$ (Figure 1A) to 3.89, 2.29, and $1.69 \mathrm{ppm}$ (Figure 1B), respectively [6]. The coordination of cod to rhodium is also supported. This chemical shift change arises because L-alanine provides an easily accessible coordination vacancy through a potential effect on the metal center [21]. On the basis of these ${ }^{1} \mathrm{H}-\mathrm{NMR}$ spectra as well as the results of the ${ }^{13} \mathrm{C}$ NMR, IR, and elemental analyses, it was concluded that the novel chiral rhodium catalyst containing cod and L-alanine ([Rh(L-alaninate)(cod)]) was synthesized successfully.

Here, we report the asymmetric polymerization of achiral phenylacetylene monomer (DoDHPA) by using the crystalline chiral Rh catalyst, as shown in Scheme 2 .

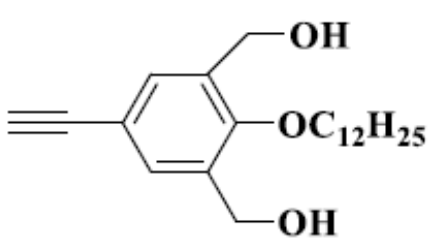

Achiral DoDHPA
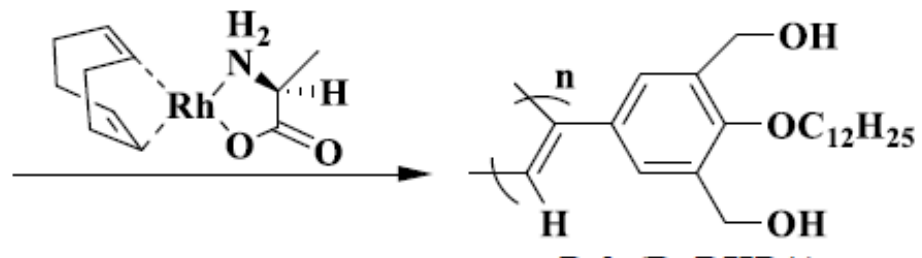

Poly(DoDHPA)

Scheme 2. Helix-sense-selective polymerization of DoDHPA by using [Rh(L-alaninate)(cod)] as catalyst.

The achiral monomer (DoDHPA) was polymerized by using the binary $[\mathrm{Rh}(\mathrm{cod}) \mathrm{Cl}]_{2} /$ (chiral amine) catalytic system, with $\left[\mathrm{Rh}(\operatorname{cod}) \mathrm{Cl}_{2}\right.$ as the main catalyst and L-prolinol, L-valinol, L-alaninol, 
or (S)-PEA as cocatalysts, to produce polymers in low yield $(8 \%-31 \%)$ with moderate $M_{\mathrm{W}}$ $2.93 \times 10^{4}-28.50 \times 10^{4}$ (Table 1, entries 1-4). Similar results were also reported by Trhlikova and Mawatari [22,23]. To obtain polymers with higher yield and $M_{\mathrm{w}}$ values, we attempted to prepare a novel high-efficiency catalyst [Rh(L-alaninate)(cod)]. We polymerized DoDHPA using the isolated [Rh(L-alaninate)(cod)] catalyst without a cocatalyst to lead a high yield (72\%) and large molecular weight $\left(55.43 \times 10^{4}\right)$, as presented in Table 1 . Similar results were obtained when a binary $\left[\mathrm{Rh}(\mathrm{nbd}) \mathrm{Cl}_{2} /\right.$ / chiral amine) catalytic system and novel isolated [Rh(L-alaninate)(nbd)] catalyst without a cocatalyst were used to polymerize DoDHPA. The isolated [Rh(L-alaninate)(nbd)] catalyst without a cocatalyst gave a high yield $(83 \%)$ and a large molecular weight $\left(245.26 \times 10^{4}\right)$. This may be due to the higher stability of $[\mathrm{Rh}(\mathrm{L}$-alaninate $)(\mathrm{cod})]$ and $[\mathrm{Rh}(\mathrm{L}$-alaninate $)(\mathrm{nbd})]$ in solution compared to the binary $[\mathrm{Rh}(\mathrm{cod}) \mathrm{Cl}]_{2} /$ (chiral amine) and $\left[\mathrm{Rh}(\mathrm{nbd}) \mathrm{Cl}_{2} /\right.$ (chiral amine) catalytic system. By contrast, the isolated $[\mathrm{Rh}(\mathrm{L}$-alaninate)(cod)] and [Rh(L-alaninate)(nbd)] used as the active species directly induces the asymmetric polymerization of DoDHPA. However, the binary $[\mathrm{Rh}(\operatorname{cod}) \mathrm{Cl}]_{2} /(\operatorname{chiral}$ amine) and $[\mathrm{Rh}(\mathrm{nbd}) \mathrm{Cl}]_{2} /$ (chiral amine) catalytic systems require coordination during the reaction so that the coordinating rate may be low. As a result, when $[\mathrm{Rh}(\mathrm{L}$-alaninate $)(\mathrm{cod})]$ and $[\mathrm{Rh}(\mathrm{L}$-alaninate)(nbd)] were used, the polymerization has more active species, enabling the polymerizations of DoDHPA with high yields and high molecular weight.

Table 1. Asymmetric polymerizations of DoDHPA with various chiral Rh catalysts ${ }^{\mathrm{a}}$.

\begin{tabular}{|c|c|c|c|c|c|c|c|}
\hline No. & Catalyst & Cocatalyst & Solvent & Yield & $M_{\mathrm{w}}^{\mathrm{b}}\left(\times 10^{4}\right)$ & $M_{\mathrm{w}} / M_{\mathrm{n}}^{\mathrm{b}}$ & {$[\theta]_{310}^{c}\left(\times 10^{-5}\right)$} \\
\hline 1 & {$[\mathrm{Rh}(\operatorname{cod}) \mathrm{Cl}]_{2}$} & (S)-PEA & Toluene & 23 & 9.82 & 2.35 & -24.70 \\
\hline 2 & & L-prolinol & Toluene & 10 & 9.83 & 3.88 & -13.16 \\
\hline 3 & & L-valinol & Toluene & 8 & 2.93 & 1.15 & -2.77 \\
\hline 4 & & L-alaninol & Toluene & 31 & 28.50 & 5.36 & 13.57 \\
\hline 5 & {$[\mathrm{Rh}(\mathrm{L}-$ alaninate $)(\mathrm{cod})]$} & none & Toluene & 72 & 55.43 & 2.14 & 55.00 \\
\hline 6 & & none & $\mathrm{CH}_{2} \mathrm{Cl}_{2}$ & 25 & 4.57 & 2.30 & 19.10 \\
\hline 7 & & none & Benzene & 39 & 15.14 & 2.64 & 4.26 \\
\hline 8 & & none & Acetone & 17 & 20.64 & 3.95 & 2.83 \\
\hline 9 [12] & {$[\mathrm{Rh}(\mathrm{nbd}) \mathrm{Cl}]_{2}$} & (R)-PEA & Toluene & 36 & 517.00 & - & 31.10 \\
\hline 10 & & L-alaninol & Toluene & 64 & 43.39 & 2.78 & 29.00 \\
\hline 11 & & L-alaninol & $\mathrm{CH}_{2} \mathrm{Cl}_{2}$ & 35 & 20.65 & 4.93 & 17.00 \\
\hline 12 & {$[\mathrm{Rh}($ L-alaninate $)(\mathrm{nbd})]$} & none & Toluene & 33 & 73.08 & 2.83 & 6.27 \\
\hline 13 & & none & $\mathrm{CH}_{2} \mathrm{Cl}_{2}$ & 83 & 245.26 & 5.25 & 79.11 \\
\hline
\end{tabular}

The CD spectra of the polymers are shown in Figure 2. The polymers exhibited Cotton effects with molar ellipticity $(\theta)\left(\mathrm{deg} \mathrm{cm}^{2} / \mathrm{dmol}\right)$ at 310 and $430 \mathrm{~nm}$. The peak at $310 \mathrm{~nm}$ may arise from a chiral position between the adjacent pendant groups [11,12]. The absorption band at $430 \mathrm{~nm}$ was assigned to the conjugated main chain. Therefore, the polymers had chirality in the main chain, that is, a one-handed helical backbone. The $(\theta)$ value of poly (DoDHPA) obtained by using the isolated $[\mathrm{Rh}(\mathrm{L}$-alaninate)(cod)] was higher (Figure 2, No. 5) than that of the polymer obtained by using the binary $[\mathrm{Rh}(\mathrm{cod}) \mathrm{Cl}]_{2} /(\mathrm{L}-$-alaninol) catalytic system (Figure 2, No. 4). When [Rh(L-alaninate)(nbd)] was used as the catalyst in $\mathrm{CH}_{2} \mathrm{Cl}_{2}$ solution, the obtained poly(DoDHPA) showed a greater molar ellipticity $[\theta]$ value than $\left[\mathrm{Rh}(\mathrm{nbd}) \mathrm{Cl}_{2} /\right.$ (L-alaninol) (Figure S16, Supplementary Materials).

When [Rh(L-alaninate)(cod)] and [Rh(L-alaninate)(nbd)] were used as catalysts, even though the Rh-N bonds dissociate, the Rh-O bonds are preserved (Chart 1 ). This differences between the bonds are due to the stronger donating and acceptor abilities of the O-atom compared to the $\mathrm{N}$-atom. The $\mathrm{Rh}-\mathrm{N}$ bond length is greater than the $\mathrm{Rh}-\mathrm{O}$ bond length, enabling proton transfer from the NH group to the coordinated monomer $[17,24]$. The synthesis and characterization of $[R h(L-a l a n i n a t e)(c o d)]$ and $[\mathrm{Rh}(\mathrm{L}-$ alaninate $)(\mathrm{nbd})]$ can confirm that the Rh complex containing the amine group may be the real active species of HSSP or SHSSP (Chart 1), providing direct evidence for our previous results [13]. Therefore, the isolated $[\mathrm{Rh}(\mathrm{L}-$-alaninate $)(\mathrm{cod})]$ and $[\mathrm{Rh}(\mathrm{L}-$ alaninate $)(\mathrm{nbd})]$ also maintains a higher 
helical selective ability than the binary $[\mathrm{Rh}(\operatorname{cod}) \mathrm{Cl}]_{2} / \mathrm{L}$-alaninol and $[\mathrm{Rh}(\mathrm{nbd}) \mathrm{Cl}]_{2} / \mathrm{L}$-alaninol catalytic system in HSSP of DoDHPA.

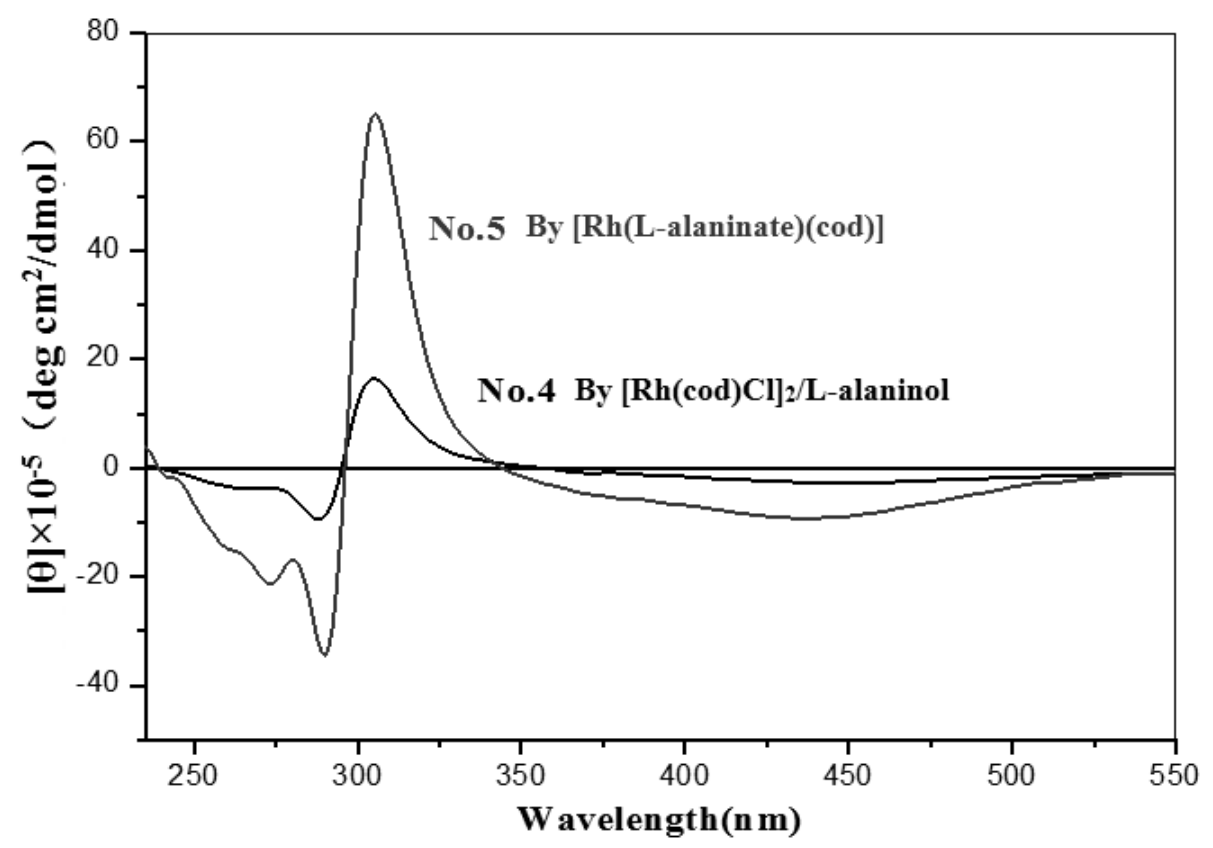

Figure 2. Circular dichroism (CD) spectra of chiral helical poly(DoDHPA) obtained using $[\mathrm{Rh}(\operatorname{cod}) \mathrm{Cl}]_{2} / \mathrm{L}$-alaninol and $[\mathrm{Rh}(\mathrm{L}$-alaninate)(cod) $]$ as catalysts (CD spectra were determined in THF solution with $1.000 \mathrm{mmol} / \mathrm{L}$ poly(DoDHPA)) (Table 1, entries 4 and 5).

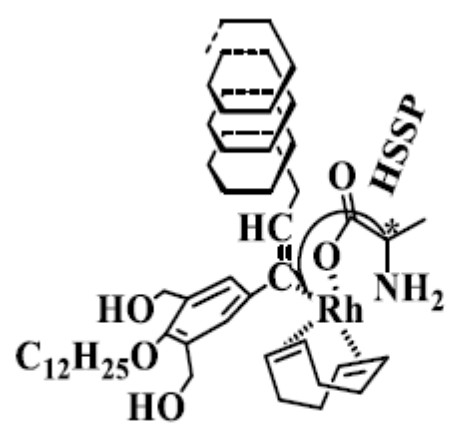

\section{Rh(cod)(L-alaninate) induced HSSP}

Chart 1. Mechanism of helix-sense-selective polymerization (HSSP) of DoDHPA by the $[\mathrm{Rh}(\mathrm{L}-$ alaninate $)(\mathrm{cod})]$ catalyst.

These findings indicate that the chiral rhodium complex with L-alaninate as the ligand is effective for HSSP. The [Rh(L-alaninate)(cod)] and [Rh(L-alaninate)(nbd)] catalyst can induce HSSP of DoDHPA.

On the other hand, we also investigated role of co-catalysts on HSSP of DoDHPA. As shown in Figure 3, when the binary $[\mathrm{Rh}(\operatorname{cod}) \mathrm{Cl}]_{2} /$ chiral amine catalytic system was used to polymerize DoDHPA, the type of chiral cocatalysts affected the $(\theta)$ value of the polymers. The $(\theta)$ value of the polymer obtained by $\left[\mathrm{Rh}(\mathrm{cod}) \mathrm{Cl}_{2} /\right.$ (S)-PEA was higher (Figure 3 , No. 1) than those obtained by using L-prolinol, L-valinol and L-alaninol (Figure 3, Nos. 2-4). This behavior may be due to the larger steric hindrance of (S)-PEA compared to those of L-prolinol, L-valinol, and L-alaninol. These findings indicated that the (S)-PEA is a good cocatalyst in the HSSP of DoDHPA. 


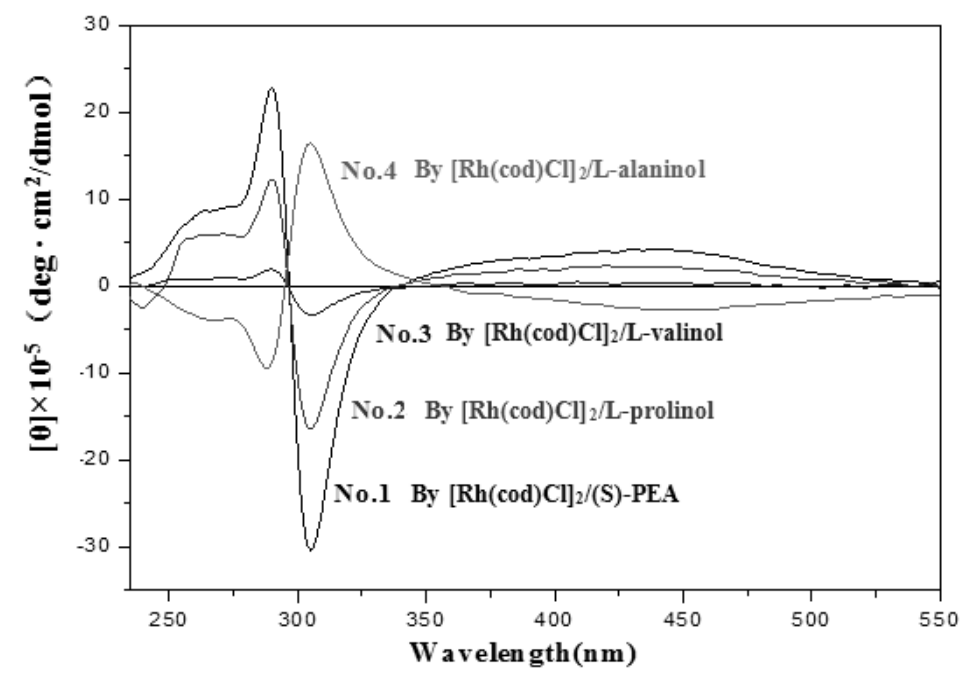

Figure 3. CD spectra of chiral poly(DoDHPA) obtained using the $[\mathrm{Rh}(\operatorname{cod}) \mathrm{Cl}]_{2} /$ (chiral amine) catalytic system (CD spectra were determined in a THF solution with $1.000 \mathrm{mmol} / \mathrm{L}$ poly(DoDHPA)) (Table 1, entries 1-4).

We also studied the effect of the solution on the HSSP of DoDHPA. When toluene was used as the polymerization solvent, $[\mathrm{Rh}(\mathrm{L}$-alaninate)(cod)] improved the catalytic performance to provide polymers with higher $M_{\mathrm{w}}$, yields and ( $\theta$ ) values (Table 1, No. 5 and Figure 4) compared to those obtained using $\mathrm{CH}_{2} \mathrm{Cl}_{2}$, benzene, and acetone as the solvents. The polarity of the solvent strongly affected the polymerization of DoDHPA. The polarity values of toluene and benzene are lower than those of the other solvents. DoDHPA and poly(DoDHPA) have better solubilities in toluene. It is important to mention that the solvents affect the catalytic activity. These differences may be due to the different solvents affecting the stability of the Rh complex acting as the active species of the asymmetric polymerization.

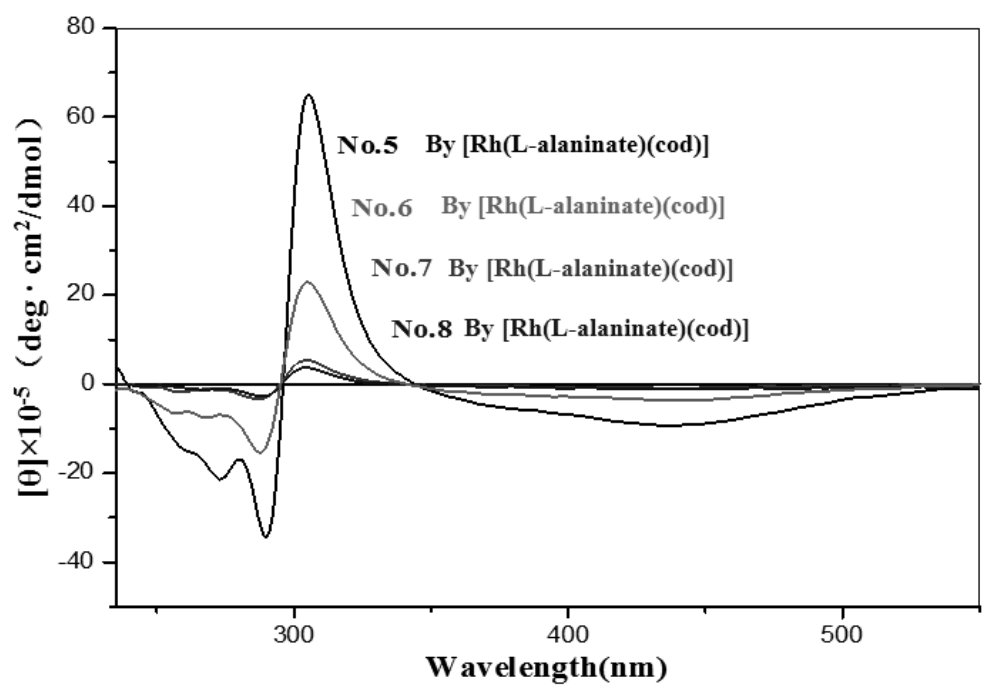

Figure 4. CD spectra of chiral helical poly(DoDHPA) obtained using the [Rh(L-alaninate)(cod)] catalyst in different solvents (CD spectra were determined in THF solution with $1.000 \mathrm{mmol} / \mathrm{L}$ poly(DoDHPA)) (Table 1, entries 5-8).

Polymerization of phenylacetylene (PA) [25] was also performed using a [Rh(L-alaninate)(cod)] catalyst in different solvents at $30^{\circ} \mathrm{C}$ for $24 \mathrm{~h}$. The obtained results are summarized in Table 2 . The yield and $M_{\mathrm{w}}$ of polymers were very high, with values of $78.6-92.5 \%$ and $10^{5}-3 \times 10^{5}$, respectively. When methanol is used as the solvent, the highest yield and $M_{\mathrm{w}}$ values were obtained. This is because 
the methanol hydroxyl and the amino group of the active species (Chart 1) can form a hydrogen bond, improving the activity of the polymerization species and increasing the polymerization yield. Additionally the surface tension and the boiling point of methanol are low, and the poly(PA) solubility in methanol is strong, which can effectively reduce the viscosity of the system and promote the polymerization. Therefore, [ $\mathrm{Rh}\left(\mathrm{L}\right.$-alaninate)(cod)] used in a $\mathrm{CH}_{3} \mathrm{OH}$ solution was a high-efficiency catalyst for the polymerization of PA.

Table 2. Polymerizations of phenylacetylene with $[\mathrm{Rh}(\mathrm{L}$-alaninate $)(\mathrm{cod})]$ as the catalyst ${ }^{\mathrm{a}}$.

\begin{tabular}{cccccc}
\hline No. & Solvent & Yield(\%) & $\boldsymbol{M}_{\mathbf{n}}{ }^{\mathbf{b}}\left(\times \mathbf{1 0}^{\mathbf{4}}\right)$ & $\boldsymbol{M}_{\mathbf{w}}{ }^{\mathbf{b}}\left(\times \mathbf{1 0}^{\mathbf{4}}\right)$ & $\boldsymbol{M}_{\mathbf{w}} \boldsymbol{M}_{\mathbf{n}}{ }^{\mathbf{b}}$ \\
\hline 1 & Toluene & 78.6 & 6.80 & 10.54 & 1.55 \\
2 & $\mathrm{CHCl}_{3}$ & 82.5 & 9.58 & 12.74 & 1.33 \\
3 & $\mathrm{CH}_{2} \mathrm{Cl}_{2}$ & 82.0 & 10.32 & 21.57 & 2.09 \\
4 & $\mathrm{THF}$ & 87.8 & 12.78 & 28.49 & 2.23 \\
5 & $\mathrm{CH}_{3} \mathrm{OH}$ & 92.5 & 17.26 & 30.21 & 1.75 \\
\hline
\end{tabular}

a $A_{\mathrm{t}} 30^{\circ} \mathrm{C}, 24 \mathrm{~h}$; [phenylacetylene] $=1.0 \mathrm{mmol},[\mathrm{Rh}]=0.010 \mathrm{mmol} .{ }^{\mathrm{b}}$ Determined by GPC correlating polystyrene standard with a THF eluent.

\section{Conclusions}

The poly(DoDHPA) which obtained using the chiral $[\mathrm{Rh}(\mathrm{L}$-alaninate)(cod)] and [Rh(L-alaninate)(nbd)] catalysts exhibited extremely high $M_{\mathrm{w}}$ and molar ellipticity values. The sense of the helix of poly(DoDHPA) was induced by the chirality sign of [Rh(L-alaninate)(cod)] and $[\mathrm{Rh}(\mathrm{L}$-alaninate)(nbd)]. Simultaneously, [Rh(L-alaninate)(cod)] and [Rh(L-alaninate)(nbd)] also exhibited high catalytic activity in phenylacetylene polymerization.

Supplementary Materials: The following are available online at http://www.mdpi.com/2073-4360/10/11/ 1223/s1, Chart S1: Chemical Structures of The Monomers (ORDHPAs), Scheme S1: Synthetic route to catalyst [Rh(L-alaninate)(nbd)], Figure S1: ${ }^{13} \mathrm{C}$ NMR spectrum of $\left[\mathrm{Rh}(\operatorname{cod}) \mathrm{Cl}_{2}\right]$ in $\mathrm{CDCl}_{3}$ at $25{ }^{\circ} \mathrm{C}$, Figure S2: FT-IR spectrum of $\left[\mathrm{Rh}(\operatorname{cod}) \mathrm{Cl}_{2}\right]$. Figure S3: ${ }^{13} \mathrm{C}$ NMR spectrum of $\left[\mathrm{Rh}\left(\mathrm{L}\right.\right.$-alaninate)(cod)] in DMSO- $d_{6}$ at $25{ }^{\circ} \mathrm{C}$, Figure S4: FT-IR spectrum of [Rh(L-alaninate)(cod)], Figure S5: ${ }^{1} \mathrm{H}$ NMR spectrum of [Rh(L-alaninate)(nbd)] in DMSO- $d_{6}$ at $25{ }^{\circ} \mathrm{C}$, Figure S6: FT-IR spectrum of [Rh(L-alaninate)(nbd)], Figure S7: ${ }^{1} \mathrm{H}$ NMR spectrum of achiral monomer DoDHPA in $\mathrm{CDCl}_{3}$ at $25^{\circ} \mathrm{C}$, Figure S8: FT-IR spectrum of achiral monomer DoDHPA, Figure S9: ${ }^{1} \mathrm{H}$ NMR spectrum of poly(DoDHPA) in 1,2-dichlorobenzene- $d_{4}$, Figure S10: FT-IR spectrum of poly(DoDHPA), Figure S11: SEM of the [Rh(L-alaninate)(cod)], Figure S12: XRD spectrum of the [Rh(L-alaninate)(cod)], Figure S13: Mass spectrum of the $[\mathrm{Rh}(\mathrm{L}-$ alaninate)(cod)], Figure S14: XRD spectrum of the [Rh(L-alaninate)(nbd)], Figure S15: SEM of the [Rh(L-alaninate)(nbd)], Figure S16: CD spectra of chiral poly(DoDHPA) obtained using the $[\mathrm{Rh}(\mathrm{nbd}) \mathrm{Cl}]_{2} /(\mathrm{L}-$ alaninol $)$ and $[\mathrm{Rh}(\mathrm{L}$-alaninate $)(\mathrm{nbd})]$ catalyst in different solvents (CD spectra were determined in a THF solution with $1.000 \mathrm{mmol} / \mathrm{L}$ poly(DoDHPA)) (Table 1, entries 10-13).

Author Contributions: Conceptualization, Q.W. and H.J.; Methodology, Y.S.; Software, Q.W.; Validation, H.J., L.M. and G.Y.; Formal Analysis, Y.W.; Investigation, S.X.; Resources, J.W.; Data Curation, Y.Z.; Writing-Original Draft Preparation, Q.W.; Writing-Review \& Editing, Q.W.; Visualization, T.A.; Supervision, H.J.; Project Administration, H.J.; Funding Acquisition, H.J.

Funding: Financial and facility support for this research came from the Fundamental Research Funds in Heilongjiang provincial universities (YSTSXK201862), the National Natural Science Foundation of China (21376127), (U1162123) and (51103076), and the Science and Technology Plan of Qiqihar City (GYGG-20602).

Conflicts of Interest: The authors declare no conflict of interest.

\section{References}

1. Ohta, T.; Nakahara, S.; Shigemura, Y.; Hattori, K.; Furukawa, I. $\alpha$-Amino acid: An affective ligand for asymmetric catalysis of transfer hydrogenation of ketones. Appl. Organomet. Chem. 2001, 15, 699-709. [CrossRef]

2. Kim, H.; Lee, D.; Lee, S.; Suzuki, N.; Fujiki, M.; Lee, C.L.; Kwak, G. Optically active conjugated polymer from solvent chirality transfer polymerization in monoterpenes. Macromol. Rapid Commun. 2013, 34, 1471-1479. [CrossRef] [PubMed] 
3. Jia, H.G.; Shi, Y.Q.; Ma, L.Q.; Wang, Y.Z.; Zang, Y.; Peng, J.J. Asymmetric polymerisation of substituted phenylacetylene using chiral $\mathrm{Rh}(2,5$-norbornadiene)(L-proline) catalyst. Chem. Pap. 2014, 69, 756-760. [CrossRef]

4. Saeed, I.; Shiotsuki, M.; Masuda, T. Effect of diene ligands in the rhodium-catalyzed polymerization of phenylacetylene. Macromolecules 2006, 39, 8977-8981. [CrossRef]

5. Jia, H.G.; Shi, Y.Q.; Ma, L.Q.; Gao, X.; Wang, Y.Z.; Zang, Y.; Peng, J.J.; Aoki, T.; Teraguchi, M.; Kaneko, T.; Masuda, T. Novel isolated, L-amino acid-ligated rhodium catalysts that induce highly helix-sense-selective polymerization of an achiral 3,4,5-trisubstituted phenylacetylene. J. Polym. Sci. Part A 2016, 54, 2346-2351. [CrossRef]

6. Ciammaichella, A.; Cardoni, V.; Leoni, A.; Tagliatesta, P. Rhodium porphyrin bound to a merrifield resin as heterogeneous catalyst for the cyclopropanation reaction of olefins. Molecules 2016, 21, 278. [CrossRef] [PubMed]

7. Nishimura, T.; Ichikawa, Y.; Hayashi, T.; Onishi, N.; Shiotsuki, M.; Masuda, T. Asymmetric polymerization of achiral arylacetylenes giving helical polyacetylenes in the presence of a rhodium catalyst with a $\mathrm{C}_{2}$-symmetric tetrafluorobenzobarrelene ligand. Organometallics 2009, 28, 4890-4893. [CrossRef]

8. Riener, K.; Hogerl, M.P.; Gigler, P.; Kuhn, F.E. Rhodium-catalyzed hydrosilylation of ketones: Catalyst development and mechanistic insights. ACS Catal. 2012, 2, 613-621. [CrossRef]

9. Onishi, N.; Shiotsuki, M.; Sanda, F.; Masuda, T. Polymerization of phenylacetylenes with rhodium zwitterionic complexes: Enhanced catalytic activity by $\pi$-acidic diene ligands. Macromolecules 2009, 42, 4071-4076. [CrossRef]

10. Jaseer, E.A.; Casado, M.A.; Al-Saadi, A.A.; Oro, L.A. Intermolecular hydroamination versus stereoregular polymerization of phenylacetylene by rhodium catalysts based on $\mathrm{N}-\mathrm{O}$ bidentate ligands. Inorg. Chem. Commun. 2014, 40, 78-81. [CrossRef]

11. Sato, T.; Aoki, T.; Teraguchi, M.; Kaneko, T.; Kim, S.Y. Role of chiral amine cocatalysts in the helix-sense-selective polymerization of a phenylacetylene using a catalytic system. Polymer 2004, 45, 8109-8114. [CrossRef]

12. Aoki, T.; Kaneko, T.; Maruyama, N.; Sumi, A.; Takahashi, M.; Sato, T.; Teraguchi, M. Helix-sense-selective polymerization of phenylacetylene having two hydroxy groups using a chiral catalytic system. J. Am. Chem. Soc. 2003, 125, 6346-6347. [CrossRef] [PubMed]

13. Jia, H.; Teraguchi, M.; Aoki, T.; Abe, Y.; Kaneko, T.; Hadano, S.; Namikoshi, T.; Ohishi, T. Three mechanisms of asymmetric polymerization of phenylacetylenes having an L-amino ether residue and two hydroxy groups. Macromolecules 2010, 43, 8353-8362. [CrossRef]

14. Zang, Y.; Ohishi, T.; Aoki, T.; Teraguchi, M.; Kaneko, T. Helix-sense-selective polymerization of substituted acetylenes by using an isolated Rh chiral initiator with an amino acid ligand. Chem. Lett. 2013, 42, 430-432. [CrossRef]

15. Teraguchi, M.; Tanioka, D.; Kaneko, T.; Aoki, T. Helix-sense-selective polymerization of achiral phenylacetylenes with two $\mathrm{N}$-alkylamide groups to generate the one-handed helical polymers stabilized by intramolecular hydrogen bonds. ACS Macro Lett. 2012, 1, 1258-1261. [CrossRef]

16. Paiaro, G.; Musco, A.; Diana, G. Chemical and structural characterization of some $\pi$-allylicderivatives of rhodium(III). J. Organomet. Chem. 1965, 4, 466-474. [CrossRef]

17. Hetterscheid, D.G.H.; Hendriksen, C.; Dzik, W.I.; Smits, J.M.M.; Eck, E.R.H.; Rowan, A.E.; Busico, V.; Vacatello, M.; Castell, V.V.A.; Segre, A.; Jellema, E.; Bloemberg, T.G.; Bruin, B. Rhodium-mediated stereoselective polymerization of "carbenes". J. Am. Chem. Soc. 2006, 128, 9746-9752. [CrossRef] [PubMed]

18. Enamullah, M.; Sharmin, A.; Hasegawa, M.; Hoshi, T.; Chamayou, A.C.; Janiak, C. Syntheses, spectroscopic studies, and crystal structures of chiral [Rh(aminocarboxylato)( $\eta^{4}$-cod)] and chiral [Rh(amino alcohol)( $\eta^{4}$-cod)]-(acetate) complexes with an example of a spontaneous resolution of a racemic mixture into homochiral helix-enantiomers. Eur. J. Inorg. Chem. 2006, 2146-2154. [CrossRef]

19. Janiak, C.; Chamayou, A.C.; Uddin, A.K.M.; Uddin, M.; Hagen, K.S.; Enamullah, M. Polymorphs, enantiomorphs, chirality and helicity in $\left[\mathrm{Rh}\{\mathrm{N}, \mathrm{O}\}\left(\eta^{4}-\mathrm{cod}\right)\right]$ complexes with $\{\mathrm{N}, \mathrm{O}\}=$ salicylaldiminato Schiff base or aminocarboxylato ligands. Dalton Trans. 2009, 3698-3709. [CrossRef] [PubMed]

20. Enamullah, M.; Hasegawa, M.; Hoshi, T.; Okubo, J. Synthetic and spectroscopic studies of $\left[\left(\eta^{4}\right.\right.$-cod)Rh(I)-amino-acidato] complexes. J. Bangladesh Chem. Soc. 2005, 18, 165-173. 
21. Jimenez, M.V.; Perez-Torrente, J.J.; Bartolome, M.I.; Vispe, E.; Lahoz, F.J.; Oro, L.A. Cationic rhodium complexes with hemilabile phosphine ligands as polymerization catalyst for high molecular weight stereoregular poly(phenylacetylene). Macromolecules 2009, 42, 8146-8156. [CrossRef]

22. Trhlikova, O.; Zednik, J.; Balcar, H.; Brus, J.; Sedlacek, J. [Rh(cycloolefin)(acac)] complexes as catalysts of polymerization of aryl- and alkylacetylenes: Influence of cycloolefin ligand and reaction conditions. J. Mol. Catal. A 2013, 378, 57-66. [CrossRef]

23. Mawatari, Y.; Motoshige, A.; Yoshida, Y.; Motoshige, R.; Sasaki, T.; Tabata, M. Structural determination of stretched helix and contracted helix having yellow and red colors of poly(2-ethynylnaphthalene) prepared with a $[\mathrm{Rh} \text { (norbornadiene)Cl] }]_{2}$-triethylamine catalyst. Polymer 2014, 55, 2356-2361. [CrossRef]

24. Jellema, E.; Budzelaar, P.H.M.; Reek, J.N.H.; Bruin, B. Rh-Mediated Polymerization of carbenes: Mechanism and stereoregulation. J. Am. Chem. Soc. 2007, 129, 11631-11641. [CrossRef] [PubMed]

25. Kishimoto, Y.; Eckerle, P.; Miyatake, T.; Kainosho, M.; Ono, A.; Ikariya, T.; Noyori, R. Well-controlled polymerization of phenylacetylenes with organorhodium(I) complexes: Mechanism and structure of the polyenes. J. Am. Chem. Soc. 1999, 121, 12035-12044. [CrossRef]

(C) 2018 by the authors. Licensee MDPI, Basel, Switzerland. This article is an open access article distributed under the terms and conditions of the Creative Commons Attribution (CC BY) license (http://creativecommons.org/licenses/by/4.0/). 